\title{
Externalised locking compression plate as an alternative to the unilateral external fixator: a biomechanical comparative study of axial and torsional stiffness
}

\section{B. F. H. Ang, J. Y. Chen, A. K. S. Yew, S. K. Chua, S. M. Chou, S. L. Chia, J. S. B. Koh, T. S. Howe}

\section{Singapore General} Hospital, Singapore and Nanyang Technological University, Singapore
B. F. H. Ang, MBBS, MRCS, MMed (Ortho),

J. Y. Chen, MBBS, MRCS, - S. K. Chua, MBBS, MMed (Ortho), $\mathrm{MCl}$,

S. L. Chia, MBBS, FRCS, PhD, J. S. B. Koh, MBBS, FRCS, FAMS T. S. Howe, MBBS, FRCS, FAMS, Orthopaedic Surgeon, Singapore General Hospital, The Academia, 20 College Road, 169856

Singapore.

A. K. S. Yew, PhD, Research

Fellow, Singapore General Hospital, The Academia, 20 College Road, 169856 Singapore. - S. M. Chou, PhD, Associate Professor, Nanyang Technological University, School of Mechanical and Aerospace Engineering, 50 Nanyang Avenue, Singapore 639798

Correspondence should be sent to B. F. H. Ang; email: benjamin.ang@mohh.com.sg

doi:10.1302/2046-3758.64.2000470 Bone Joint Res 2017;6:216-223.

\section{Objectives}

External fixators are the traditional fixation method of choice for contaminated open fractures. However, patient acceptance is low due to the high profile and therefore physical burden of the constructs. An externalised locking compression plate is a low profile alternative. However, the biomechanical differences have not been assessed. The objective of this study was to evaluate the axial and torsional stiffness of the externalised titanium locking compression plate (ET-LCP), the externalised stainless steel locking compression plate (ESSLCP) and the unilateral external fixator (UEF).

\section{Methods}

A fracture gap model was created to simulate comminuted mid-shaft tibia fractures using synthetic composite bones. Fifteen constructs were stabilised with ET-LCP, ESS-LCP or UEF (five constructs each). The constructs were loaded under both axial and torsional directions to determine construct stiffness.

\section{Results}

The mean axial stiffness was very similar for UEF $(528 \mathrm{~N} / \mathrm{mm})$ and ESS-LCP $(525 \mathrm{~N} / \mathrm{mm})$, while it was slightly lower for ET-LCP $(469 \mathrm{~N} / \mathrm{mm})$. One-way analysis of variance (ANOVA) testing in all three groups demonstrated no significant difference $(F(2,12)=2.057, p=0.171)$.

There was a significant difference in mean torsional stiffness between the UEF $(0.512 \mathrm{Nm} /$ degree $)$, the ESS-LCP $(0.686 \mathrm{Nm} /$ degree $)$ and the ET-LCP $(0.639 \mathrm{Nm} /$ degree $)$, as determined by one-way ANOVA $(F(2,12)=6.204, p=0.014)$. A Tukey post hoc test revealed that the torsional stiffness of the ESS-LCP was statistically higher than that of the UEF by $0.174 \mathrm{Nm} /$ degree $(p=0.013)$. No catastrophic failures were observed.

\section{Conclusion}

Using the LCP as an external fixator may provide a viable and attractive alternative to the traditional UEF as its lower profile makes it more acceptable to patients, while not compromising on axial and torsional stiffness.

Cite this article: Bone Joint Res 2017;6:216-223.

Keywords: Externalised locking compression plate, External fixator, Biomechanical testing, Axial stiffness, Torsional stiffness, Supercutaneous plating

\section{Article focus}

External fixators are the traditional fixation method of choice for contaminated open fractures. However, patient acceptance is low due to the high profile and therefore physical burden of the constructs.

- An externalised locking compression plate is a low profile alternative. However, the biomechanical differences have not been assessed.

- The objective of this study was to evaluate the axial and torsional stiffness of the externalised titanium locking compression plate (ET-LCP), the externalised stainless steel locking compression plate (ESS-LCP) and the unilateral external fixator (UEF). 


\section{Key messages}

- The externalised LCP has a similar axial stiffness to that of the UEF.

- The torsional stiffness of the ESS-LCP is higher than that of the UEF.

- Using the LCP as an external fixator may provide a viable and attractive alternative to the traditional UEF as its lower profile makes it more acceptable to patients, while not compromising on axial and torsional stiffness.

\section{Strengths and limitations}

- First biomechanical study comparing the axial and torsional stiffness of externalised locking compression plate with an external fixator.

- Four-point bending and cyclic fatigue testing not performed due to equipment limitations.

\section{Introduction}

External fixators are the traditional fixation method of choice for contaminated open fractures and in certain closed fractures with severe soft-tissue injuries. External fixators allow for better soft-tissue management and preservation of blood supply to the fractured bone.1,2 They can be used for temporary or definitive fixation. However, acceptance of external fixation is low due to the high profile of the constructs, which makes it obstructive and inconvenient during ambulation and dressing. The high profile of the external fixator is secondary to the length of the Schanz pins and the size of the clamps, which also limit how close to the bone the rod can be placed. Besides the obstructive nature of the high profile construct, some patients are also self-conscious of these fixators and find them less socially acceptable..$^{2-8}$

Various locking plates have been used as a low profile alternative, particularly the locking compression plate (LCP) which has the advantage of a lower profile and therefore poses less of an inconvenience during dressing and ambulation. The externalised LCP is also a less costly option compared with the external fixator. ${ }^{8}$ The main drawback of using the LCP, compared with the external fixator, is the inability to perform subsequent adjustments of the bone-to-plate offset and distraction/compression at the fracture site.

Stiffness (the measurement of force per unit displacement in Newtons/metre) of the construct is extremely important because it is related to the relative micromotion at the fracture site, which has a direct effect on the biology of fracture healing. Too much movement at the fracture site, which can be caused inadvertently by too high an offset between the bone and the plate, can result in fibrous union. Delayed union or even nonunion will eventually lead to fatigue failure of the implant.

Bottlang et $\mathrm{a}^{9}$ report that, even for the same implant, the reported stiffness values can vary greatly as they are affected by the test setup. This is particularly the case when the stiffness is calculated from the displacement of the loading actuator. Actuator displacement represents deformation along the entire test specimen and can grossly overestimate the actual motion at the fracture site. ${ }^{9}$ Studies which demonstrate a higher stiffness used an extensometer to determine displacement at the fracture site which is more accurate. ${ }^{10,11}$

The stiffness of the LCP used in a traditional manner has been quoted as being as low as $42 \mathrm{~N} / \mathrm{mm}$ to as high as $3300 \mathrm{~N} / \mathrm{mm} .9,12-17$ The methodologies in these studies are different, including the loading conditions, as are the measurements of displacement (either across the entire construct or at the fracture gap) used in calculating the stiffness of the construct. Other differences include the use of monocortical screws in some studies, ${ }^{16}$ the use of different implants (length, size, type), and different screw configurations/densities.

To the best of our knowledge, there has only been one study performed investigating the mechanical properties of a LCP when used as an external fixation device. However, no attempt was made to compare it with the traditional carbon rod and Schanz pin external fixator construct. ${ }^{18}$ This direct comparison under standardised conditions gives us important data on the relative mechanical properties of the externalised LCP and external fixator constructs. Lower limb biomechanics studies reveal that forces at the fracture site are predominantly compressive during two-legged stance, while transverse and torsional contributions to load bearing are relatively low. ${ }^{16}$ The objective of this study is to compare the axial and torsional stiffness of the externalised LCP and the unilateral external fixator (UEF).

We hypothesise that the externalised LCP has a similar axial and torsional stiffness to that of the UEF, which favours its use as an external fixation device.

\section{Materials and Methods}

Fracture model. The tibia was chosen as it is the most suitable bone for using the externalised LCP as an external fixator, being superficial and having only a thin layer of soft tissue overlying it. A fracture gap model was created to simulate comminuted mid-shaft tibia fractures using synthetic composite bones. ${ }^{19,20}$ Fourthgeneration, large-sized left tibia synthetic composite bones, model \#3402 (Sawbones; Pacific Research Laboratories Inc., Vashon, Washington), $405 \mathrm{~mm}$ in length, $84 \mathrm{~mm}$ wide at the proximal tibia, $58 \mathrm{~mm}$ wide at the distal tibia, $28 \mathrm{~mm}$ wide at the middle of the tibial shaft, and $10 \mathrm{~mm}$ in canal diameter, were used for this study.

The specimens were cut at the mid point to create a $20 \mathrm{~mm}$ gap, simulating a comminuted diaphyseal fracture and ensuring that there was no contact between the two ends of the fracture gap during axial loading. 


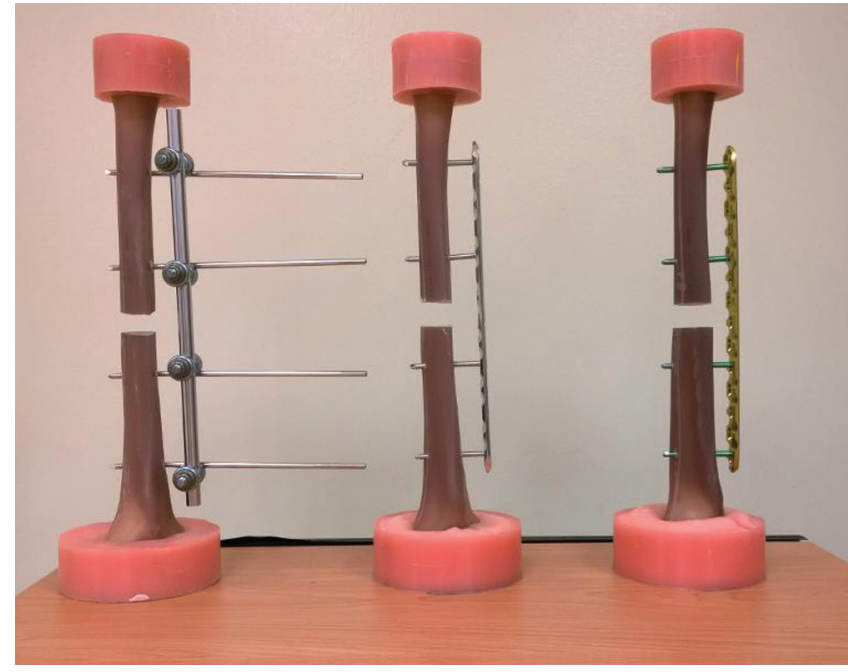

Fig. 1

Photograph of constructs potted in dental plaster. Left: unilateral external fixator; middle: externalised stainless steel locking compression plate; right: externalised titanium locking compression plate.

Implants. A power analysis was undertaken before this study was carried out, based on the results from a preliminary study. To detect a $16 \%$ reduction in axial stiffness from a baseline of $530 \pm 20 \mathrm{~N} / \mathrm{mm}$ at a power of 0.80 , a sample size of at least four specimens in each group would be required. This calculation was made for a twosided test with a type I error of 0.05 . In view of possible sampling errors in the preliminary study, five specimens in each group were chosen to provide for these possible sampling errors. ${ }^{21}$

Fifteen tibias were divided into three groups of five, with fixation either by externalised titanium locking compression plate (ET-LCP), the externalised stainless steel locking compression plate (ESS-LCP) or the unilateral external fixator (UEF).

Five tibias were stabilised with a titanium $260 \mathrm{~mm}$ 14-hole broad 4.5/5 mm LCP (Synthes, Switzerland), with $5 \mathrm{~mm}$ diameter titanium locking screws in the third and seventh locking holes from the middle of the LCP, on both sides of the fracture. Five tibias were stabilised with a stainless steel $260 \mathrm{~mm}$ 14-hole broad 4.5/5 mm LCP (Synthes), with $5 \mathrm{~mm}$ diameter stainless steel locking screws in the third and seventh locking holes from the middle of the LCP, on both sides of the fracture. Both LCPs are $260 \mathrm{~mm}$ long, $5.2 \mathrm{~mm}$ thick, $17.5 \mathrm{~mm}$ wide and have a hole spacing of $18 \mathrm{~mm}$.

In our control model, five tibias were stabilised with external fixation (Synthes). Two stainless steel standard $5 \mathrm{~mm}$ diameter Schanz pins were used per fragment and attached with standard clamps to one standard $11 \mathrm{~mm}$ diameter stainless steel rod. The positions of the Schanz pins correspond to the locking screws in the third and seventh locking holes from the middle of the LCP. The choice of the third and seventh locking holes from the middle of the LCP adheres to the Arbeitsgemeinschaft für
Osteosynthesefragen (AO) principles of external fixation in having a pin near (third locking hole from the middle of the LCP) and far (seventh locking hole from the middle of the LCP) from the fracture site in both fragments, while being limited by the zone of injury and the length of the tibia. ${ }^{22}$ This same configuration is used in the only other study $^{18}$ in the literature investigating the stiffness of the externalised LCP.

The AO recommendation for traditional LCP fixation is to have a minimum of three screws in each fragment on either side of the fracture but, for the purposes of comparison, the same two-screws/Schanz pin positions were used in each fragment on either side of the fracture. We recognise that this is a limitation and an additional screw may influence the axial or torsional stiffness of the construct.

Standard AO techniques were used for the fixation of the constructs, where all screw holes were prepared with drilling using a $4.3 \mathrm{~mm}$ drill bit through a locking barrel, and all screws that were used were fully threaded selftapping $5 \mathrm{~mm}$ diameter locking screws (Synthes). The torque applied to each screw was standardised to $4 \mathrm{Nm}$ using a torque-controlling screwdriver to lock the screw to the plate as recommended by the manufacturer. The screws used were slightly longer than the measured length to ensure that there was adequate purchase of the far cortex. The Schanz pins were advanced three 'turns' or approximately $3 \mathrm{~mm}$ once they had penetrated the far cortex to ensure adequate purchase.

A $20 \mathrm{~mm}$ offset distance is kept between the bone and the plates/external fixator rods at the fracture site to account for soft tissue. This also allows for soft-tissue swelling without any interference with the construct. ${ }^{23}$ We chose a $20 \mathrm{~mm}$ offset rather than a $30 \mathrm{~mm}$ offset in order to increase the stability of the construct and to prevent excessive micromotion at the fracture site. The lower profile plate also had the previously mentioned advantages of less obstruction during ambulation, and ease of fitting under clothing. Our choice of $20 \mathrm{~mm}$ was able to fit with adequate clearance from the soft tissue due to the subcutaneous nature of the anterior tibial border.

Mechanical testing. For mechanical testing, the proximal and distal ends of each tibia were potted in dental plaster (Fig. 1). Including the dental plaster, the total length of the construct was $465 \mathrm{~mm}$. The position of the tibia was such that the line of action for the load went through the central axis of the construct, simulating the mechanical axis of the tibia. To limit all unwanted movement during testing, both ends of the tibia sawbone were potted.

Following fixation, the constructs were axially loaded using an Instron 5565 uniaxial mechanical testing machine (Instron, Norwood, Massachusetts) (Fig. 2). Axial loading was applied by directly placing the construct under the load cell.

In a pilot study, the static load to failure was determined to be comfortably in excess of $2100 \mathrm{~N}$. Hence, an 


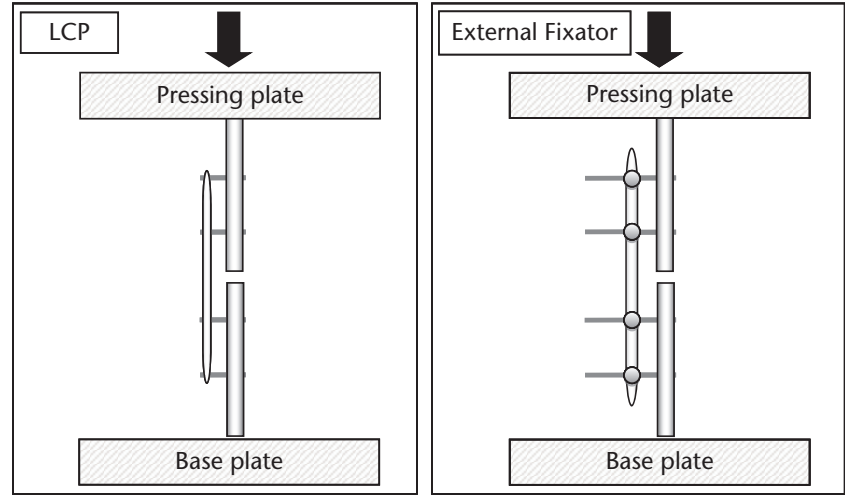

Fig. 2

Diagram of constructs undergoing loading.

axial load of up to $2100 \mathrm{~N}$ was chosen, corresponding to three times the body weight of a $70 \mathrm{~kg}$ person, which is more than the world average weight of $62 \mathrm{~kg} .{ }^{24}$ The stiffness testing within this chosen loading range would not be confounded by catastrophic implant failure, as defined by implant failure or screw cut-out.

For the quasi-static testing, axial loading force was gradually increased from $0 \mathrm{~N}$ to $2100 \mathrm{~N}$ at $20 \mathrm{~N} / \mathrm{s}$ for six cycles. Interfragmentary motion at the fracture site was recorded at the far cortex, opposite, furthest from, the implant, using a contact extensometer with $0.01 \mathrm{~mm}$ resolution. ${ }^{25}$ The far cortex was preferred over the near cortex as there is greater interfragmentary motion, and thus resulted in a lower calculated stiffness than the near cortex.

Torsional testing was performed using a customised jig. Torque was applied up to $5 \mathrm{Nm}$, with every increment of $0.2 \mathrm{Nm}$ and rotation of the specimen at the fracture site tracked using electromagnetic sensors (3D Guidance Model 130; Ascension Technology Corporation, Shelburne, Vermont). Torsional stiffness is determined as the average slope of the torque-rotation curve, and is expressed in $\mathrm{Nm} /$ degree. Each specimen was tested six times in axial compression and six times in torsion.

Data were collected on a personal computer at a rate of $100 \mathrm{~Hz}$. The first three cycles each in axial compression and in torsion were discarded to account for system settling. The gradient of the load-displacement curves of the final three cycles was analysed and the average axial stiffness for each specimen was calculated. Torsional stiffness was calculated by dividing the torque by the degree of rotation.

Statistical analysis was performed using SPSS 17.0 (SPSS Inc., Chicago, Illinois). One-way analysis of variance (ANOVA) was used to compare the three groups for difference in axial and torsional stiffness, and post hoc testing was performed using Tukey if necessary. One-way ANOVA was chosen as it was the appropriate test to determine significant differences between the means of the three independent groups. A level of significance of $p<0.05$ was used as the threshold for statistical significance.

\section{Results}

The mean axial stiffness was very similar for UEF (528, standard deviation (SD) $42 \mathrm{~N} / \mathrm{mm}$ ) and ESS-LCP (525, SD $69 \mathrm{~N} / \mathrm{mm}$ ), while it was slightly lower for ET-LCP (469, SD $37 \mathrm{~N} / \mathrm{mm}$ ). Table I shows the results in table form. Figure 3 shows the typical graph of compressive load (N) against displacement at the fracture site $(\mathrm{mm})$. One-way ANOVA testing of the stiffness in all three groups demonstrated no significant difference $(F(2,12)=2.057, p=0.171)$.

There was a significant difference in mean torsional stiffness between the UEF (0.512, SD $0.104 \mathrm{Nm} /$ degree), the ESS-LCP $(0.686$, SD $0.032 \mathrm{Nm} /$ degree $)$ and the ET-LCP (0.639, SD $0.089 \mathrm{Nm} /$ degree), as determined by one-way ANOVA $(F(2,12)=6.204, p=0.014)$. Table II shows the results in table form.

Table I. Results for axial stiffness

\begin{tabular}{|c|c|c|c|c|c|}
\hline Construct & Specimen & Axial stiffness ( $\mathbf{N} / \mathbf{m m})$ & Mean axial stiffness $(\mathrm{N} / \mathrm{mm})$ & Standard deviation $(\mathrm{N} / \mathrm{mm})$ & p-value \\
\hline & & & & & 0.171 \\
\hline \multicolumn{6}{|c|}{ Unilateral external fixator } \\
\hline & 1 & 488 & 528 & 42 & \\
\hline & 2 & 493 & & & \\
\hline & 3 & 576 & & & \\
\hline & 4 & 511 & & & \\
\hline & 5 & 571 & & & \\
\hline \multicolumn{6}{|c|}{ Externalised Stainless Steel LCP } \\
\hline & 1 & 427 & 525 & 69 & \\
\hline & 2 & 479 & & & \\
\hline & 3 & 591 & & & \\
\hline & 4 & 553 & & & \\
\hline & 5 & 573 & & & \\
\hline \multicolumn{6}{|c|}{ Externalised Titanium LCP } \\
\hline & 1 & 446 & 469 & 37 & \\
\hline & 2 & 489 & & & \\
\hline & 3 & 476 & & & \\
\hline & 4 & 419 & & & \\
\hline & 5 & 515 & & & \\
\hline
\end{tabular}

LCP, locking compression plate 


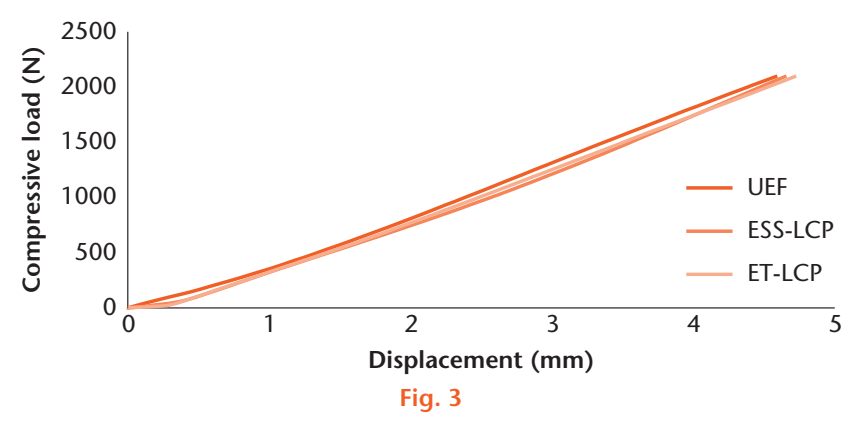

Typical graph of compressive load $(\mathrm{N})$ against displacement at fracture site $(\mathrm{mm})$ (ET-LCP, externalised titanium locking compression plate; ESS-LCP, externalised stainless steel locking compression plate; UEF, unilateral external fixator).

A Tukey post hoc test revealed that the torsional stiffness of the ESS-LCP was statistically higher than that of UEF by 0.174 , sD $0.051 \mathrm{Nm} /$ degree $(p=0.013)$. However, there were no statistically significant differences between the UEF and ET-LCP or between the ESS-LCP and ET-LCP.

No catastrophic failures, as defined by implant failure or screw cut-out, were observed in any of the three groups under both testing protocols.

\section{Discussion}

The technique of placing a plate outside the skin was first reported as the Zespol osteosynthesis system which had been developed in Poland in the 1970s. ${ }^{26-28}$ There have been several case series reporting the use of the externalised LCP as an external fixator in various regions of the body.7,29,30 However, the most common region is the tibia. 2,4-6,8,31,32 Our experience with the externalised LCP as an external fixator is also in the tibia. There have been several comparisons made between the externalised LCP and traditional external fixators. ${ }^{1,4}$ However, the stiffness of external locked plating is not clear ${ }^{2}$ as mechanical testing was not reported in the case reports and case series.
Studies involving the mechanical properties of fracturefixation constructs provide important information, which helps with our clinical decision-making. Few papers report on the stiffness of external fixators, with several historical studies indicating the range from $50 \mathrm{~N} / \mathrm{mm}$ to $400 \mathrm{~N} / \mathrm{mm} .{ }^{34-36}$ According to a study by Peindl et al, ${ }^{12}$ the LCP had a stiffness of $264 \mathrm{~N} / \mathrm{mm}$, which was greater than a hybrid construct (a $165 \mathrm{~mm}$ "3/4" ring, two $2.0 \mathrm{~mm}$ cross wires tensioned to $130 \mathrm{~kg}$ oriented at $65^{\circ}$ to each other, and one $5 \mathrm{~mm}$ Schanz "drop pin" and a "V-configured" carbon fiber rod frame), although the difference was not statistically significant. Therefore, by externalising the LCP and increasing the length of the screw between the plate and the bone, we believe the stiffness would decrease, 1,13,16 and we postulate that it would be comparable with that of an external fixator.

In the fracture model we have presented, a comminuted fracture with a shaft defect was simulated without the possibility of bony contact. Therefore, our loading model primarily tested the stability of the bone-implant construct, where interfacing of the proximal and distal fragment was achieved through the UEF or the externalised LCP (ESS-LCP or ET-LCP). Based on this model system, results of this present study support the hypothesis that there was no significant difference in axial stiffness between the UEF, the ESS-LCP and the ET-LCP. There is also no significant difference in torsional stiffness between the UEF and the ET-LCP. However, the torsional stiffness of the ESS-LCP is significantly higher than that of the UEF.

The axial stiffness of the UEF in our study is slightly higher but comparable with that in the literature, reported to be in the range of $50 \mathrm{~N} / \mathrm{mm}$ to $400 \mathrm{~N} / \mathrm{mm} .^{32-}$ 35 We believe that the use of only one rod and a short distance of $20 \mathrm{~mm}$ between the bone and the rod may explain our findings of slightly higher construct stiffness. ${ }^{1,13,16}$ Another possible explanation for the higher

Table II. Results for torsional stiffness

\begin{tabular}{|c|c|c|c|c|c|}
\hline Construct & Specimen & $\begin{array}{l}\text { Torsional stiffness } \\
\left(\mathrm{Nm} /{ }^{\circ}\right)\end{array}$ & $\begin{array}{l}\text { Average torsional stiffness } \\
\left(\mathrm{Nm} /{ }^{\circ}\right)\end{array}$ & $\begin{array}{l}\text { Standard deviation } \\
\left(\mathrm{Nm} /{ }^{\circ}\right)\end{array}$ & p-value \\
\hline & & & & & 0.014 \\
\hline \multicolumn{6}{|l|}{ Unilateral external fixator } \\
\hline & 1 & 0.462 & 0.512 & 0.104 & \\
\hline & 2 & 0.615 & & & \\
\hline & 3 & 0.583 & & & \\
\hline & 4 & 0.543 & & & \\
\hline & 5 & 0.358 & & & \\
\hline \multicolumn{6}{|c|}{ Externalised stainless steel LCP } \\
\hline & 1 & 0.646 & 0.686 & 0.032 & \\
\hline & 2 & 0.673 & & & \\
\hline & 3 & 0.710 & & & \\
\hline & 4 & 0.727 & & & \\
\hline & 5 & 0.675 & & & \\
\hline \multicolumn{6}{|l|}{ Externalised titanium LCP } \\
\hline \multirow[t]{5}{*}{ Externalised titanium LCP } & 1 & 0.493 & 0.639 & 0.089 & \\
\hline & 2 & 0.690 & & & \\
\hline & 3 & 0.656 & & & \\
\hline & 4 & 0.632 & & & \\
\hline & 5 & 0.723 & & & \\
\hline
\end{tabular}

LCP, locking compression plate 
construct stiffness in our study could be our use of an extensometer to measure fracture site displacement, which results in a more accurate but higher stiffness value compared with the other studies which used actuator displacement instead.

The axial stiffness of the ESS-LCP in our study $(525 \mathrm{~N} / \mathrm{mm})$ is higher than that found in the only other study $(112 \mathrm{~N} / \mathrm{mm})$ in the literature which investigated the biomechanical properties of an externalised LCP. ${ }^{18}$ The reasons for this include the use of a greater offset of $30 \mathrm{~mm}$ between the bone and the plate in this other study, and the use of actuator displacement instead of an extensometer, resulting in a lower measured construct stiffness. That study made no attempt to measure the torsional stiffness of the externalised LCP.

We acknowledge a high variability in the stiffness of the different specimens of the same construct. While every effort was made to produce identical specimens, variability in specimen stiffness is expected due to inadvertent small differences in fixation positions and variability in sawbones/implants. Multiple specimens were tested multiple times to reduce any error.

To our knowledge, there is no study in the literature documenting the torsional stiffness of the externalised LCP. The torsional stiffness of the LCP used in the traditional manner is reported in the literature to be in the range of $0.1 \mathrm{Nm} /$ degree to $6 \mathrm{Nm} /$ degree. ${ }^{11,16,17,36}$ The torsional stiffness of all of the constructs in our study is within this range, but at the lower end of the spectrum. This is to be expected as the torsional stiffness is anticipated to be lower as the offset between the bone and the plate is increased.

Our study shows that the ESS-LCP has a significantly higher torsional stiffness than the UEF. This, however, does not adversely affect the use of the ESS-LCP as an alternative to the UEF, as the increased stiffness is still well within the range of torsional stiffness of the LCP and thus should not compromise fracture healing.

Although not statistically significant, the observed lower axial and torsional stiffness of ET-LCP when compared with those of ESS-LCP was expected and this is due to titanium's lower Young's modulus in contrast with that of stainless steel. As the Young's modulus of stainless steel is approximately twice that of titanium, we would expect the stiffness of stainless steel to be approximately twice that of titanium. However, our study showed that the axial stiffness of the ESS-LCP is only about 1.12 times that of ET-LCP while the torsional stiffness of the ESS-LCP is 1.21 times that of the ET-LCP. Another study, by Hoffmeier et al ${ }^{14}$ also showed that their stainless steel implant has 1.3 times the stiffness of their titanium implant. We postulate that there are several other factors which may affect the calculations, and thus the difference in implant material alone does not account for a difference in the calculated stiffness.
There are several similarities between the UEF and the externalised LCP. Both systems rely on fixed-angle stabilisation between Schanz pins or screws and the rod or plate that spans the fracture. The rod or plate is suspended at a fixed distance over the bone and thus there is neither compression nor resultant compromise on the periosteal blood supply. ${ }^{37-39}$ Both techniques adopt a minimally invasive implantation technique and rely on secondary bone healing with callus formation. ${ }^{41}$ To achieve a suitable mechanical environment for secondary bone healing, both techniques allow modulation of construct stiffness to a certain degree. ${ }^{41}$

However, the extent, range and methods to which stiffness can be modulated differ between the two constructs. Changing the inter-pin distance and the distance of the pin to the fracture site can change the stiffness of the fixation construct. ${ }^{42}$ It is more difficult to modify the stiffness of the externalised LCP as there is a limited number of locking screw holes which may be used. The removal of screws, the usage of titanium instead of stainless steel, and the use of a longer bridge span are all methods of decreasing the stiffness of the externalised LCP. Increasing the number of rods in the construct to increase the stiffness of the external fixators is not possible for the externalised LCP. Modifying the height of the $\mathrm{rod} /$ plate is also much easier with the external fixator.

Another difference is that use of the externalised LCP is technically challenging as compared with external fixation as it requires a good reduction before fixation, due to the limited adjustments that can be made after fixation. The high flexibility due to the adjustable clamps and the easy implantation technique are advantages of the external fixator.

In 1996, Kowalski et al ${ }^{23}$ concluded that when the noncontact plate is elevated $20 \mathrm{~mm}$ from the bone surface it behaves similarly to a small external fixator, but does not provide the stiffness and strength necessary for supporting the loads applied to lower extremity. However, in their study, the configuration of the non-contact plate and external fixator is vastly different, including the use of a short plate with all the screws close to the fracture site for the non-contact plate, compared with a longer external fixator with Schanz pins near and far from the fracture site. The current LCP in the market is also vastly different from the non-contact plate used in that study.

Our study has shown that the externalised LCP is able to withstand up to three times the bodyweight of an average $70 \mathrm{~kg}$ adult on axial loading only, without catastrophic failure, opening up the possibility that it may provide enough stiffness and strength to allow partial weight bearing initially, and progression to full weightbearing. However, further mechanical testing is required to ascertain the fatigue strength.

Ahmad et $\mathrm{al}^{15}$ reported that a $5 \mathrm{~mm}$ plate elevation decreased construct strength in axial compression by 
$63 \%$. Their study, as with most other biomechanical studies that compared LCP elevated up to $20 \mathrm{~mm}$ with LCPs fixed to bone, observed decreased strength and stiffness in axial compression. However, no studies have made direct comparison with external fixators. Furthermore, the configurations are mostly with shorter plates with many screws close to the fracture site.

In a similar experimental set-up performed by Bottlang et al, ${ }^{13}$ the axial stiffness of a LCP with a $1 \mathrm{~mm}$ offset from the bone was $2900 \mathrm{~N} / \mathrm{mm}$. With the offset increased to $20 \mathrm{~mm}$ in our study, our calculated axial stiffness is correspondingly much lower.

This study had several limitations. First, it only tests the axial and torsional stiffness of the constructs. Ideally, we would like to test the constructs in four-point bending as well. However, limitations of laboratory equipment did not allow us to do so. Second, as with all biomechanical studies, the artificially applied load used in this model may not represent the multifaceted manner of loading that occurs in vivo. During fatigue tests, a combined load regime of both axial compression and torsion acting on the construct is likely to decrease the life of the implant.

Synthetic bone was used instead of cadaver tibias to eliminate variations in geometry and in material properties associated with human tibias, so that any differences found in testing could be attributed to the fixation devices. The use of Sawbones for mechanical testing is well established ${ }^{43,44}$ and minimises the variation in stiffness found in cadaveric bones with differences in age and bone quality. ${ }^{45}$ These large-size fourth-generation composite replicate bones exhibited intra-specimen variations of less than $10 \%$ for all cases and were also found to have similar mechanical properties to healthy adult bones, and thus are close to ideal replicas for standardisation in biomechanical analyses. ${ }^{19,20}$

Although this model did not take into account the actual muscle forces acting on the tibial diaphysis, we feel that it was appropriate for comparing the relative stability and stiffness of the three construct groups.

There are several case reports and case series of the externalised LCP being used as an external fixator in current practice. However, there has been limited mechanical evidence supporting this practice, with only one study ${ }^{18}$ in the literature evaluating the biomechanical properties of the externalised LCP and none comparing it with an external fixator.

This study provides biomechanical evidence to support the use of LCP as an external fixator. We found that the axial and torsional stiffness of the externalised LCP are comparable with those of the external fixator and thus may provide a viable alternative.

In conclusion, using the externalised LCP as an external fixator may provide a viable and attractive alternative to traditional UEF as its lower profile makes it more acceptable to patients, while not compromising on axial and torsional stiffness.

\section{References}

1. Schmal H, Strohm PC, Jaeger M, Südkamp NP. Flexible fixation and fracture healing: do locked plating 'internal fixators' resemble external fixators? J Orthop Trauma 2011;25:S15-S20.

2. Qiu XS, Yuan $\mathbf{H}$, Zheng $\mathbf{X}$, et al. Locking plate as a definitive external fixator for treating tibial fractures with compromised soft tissue envelop. Arch Orthop Trauma Surg 2014;134:383-388.

3. Woon CY, Wong MK, Howe TS. LCP external fixation-external application of an internal fixator: two cases and a review of the literature. J Orthop Surg Res 2010;5:19.

4. Apivatthakakul T, Sananpanich K. The locking compression plate as an external fixator for bone transport in the treatment of a large distal tibial defect: a case report. Injury 2007:38:1318-1325.

5. Zhou Y, Wang Y, Liu L, et al. Locking compression plate as an external fixator in the treatment of closed distal tibial fractures. Int Orthop 2015;39:2227-2237.

6. Zhang J, Ebraheim NA, Li M, et al. External Fixation Using a Locking Plate: A Reliable Way in Treating Distal Tibial Fractures. J Orthop Trauma 2015;29:e454-e458.

7. Sirisreetreerux N, Sa-Ngasoongsong $\mathbf{P}$, Chanplakorn $\mathbf{P}$, et al. Using a reconstruction locking compression plate as external fixator in infected open clavicle fracture. Orthop Rev (Pavia) 2013:5:52-55.

8. Tulner SA, Strackee SD, KIoen P. Metaphyseal locking compression plate as an external fixator for the distal tibia. Int Orthop 2012;36:1923-1927.

9. Bottlang M, Doornink J, Lujan TJ, et al. Effects of construct stiffness on healing of fractures stabilized with locking plates. J Bone Joint Surg [Am]2010;92-A:12-22.

10. Koval KJ, Hoehl JJ, Kummer FJ, Simon JA. Distal femoral fixation: a biomechanical comparison of the standard condylar buttress plate, a locked buttress plate, and the 95-degree blade plate. J Orthop Trauma 1997;11:521-524.

11. Stoffel K, Lorenz KU, Kuster MS. Biomechanical considerations in plate osteosynthesis: the effect of plate-to-bone compression with and without angular screw stability. J Orthop Trauma 2007;21:362-368.

12. Peindl RD, Zura RD, Vincent A, et al. Unstable proximal extraarticular tibia fractures: a biomechanical evaluation of four methods of fixation. J Orthop Trauma 2004;18:540-545.

13. Bottlang M, Doornink J, Fitzpatrick DC, Madey SM. Far cortical locking can reduce stiffness of locked plating constructs while retaining construct strength. J Bone Joint Surg [Am]2009;91-A:1985-1994.

14. Hoffmeier KL, Hofmann GO, Mückley T. Choosing a proper working length can improve the lifespan of locked plates. A biomechanical study. Clin Biomech (Bristol, Avon) 2011;26:405-409.

15. Ahmad M, Nanda R, Bajwa AS, et al. Biomechanical testing of the locking compression plate: when does the distance between bone and implant significantly reduce construct stability? Injury 2007;38:358-364.

16. Stoffel K, Dieter U, Stachowiak G, et al. Biomechanical testing of the LCP-how can stability in locked internal fixators be controlled? Injury 2003;34:B11-B19.

17. Schmidt U, Penzkofer R, Bachmaier S, Augat P. Implant material and design alter construct stiffness in distal femur locking plate fixation: a pilot study. Clin Orthop Relat Res 2013;471:2808-2814.

18. Kanchanomai C, Phiphobmongkol V. Biomechanical evaluation of fractured tibia externally fixed with an LCP. J Appl Biomech 2012;28:587-592.

19. Gardner MP, Chong AC, Pollock AG, Wooley PH. Mechanical evaluation of large-size fourth-generation composite femur and tibia models. Ann Biomed Eng 2010;38:613-620.

20. Heiner AD. Structural properties of fourth-generation composite femurs and tibias. J Biomech 2008;41:3282-3284.

21. Faul F, Erdfelder E, Buchner A, Lang A-G. Statistical power analyses using G*Power 3.1: tests for correlation and regression analyses. Behav Res Methods 2009;41:1149-1160.

22. Ruedi TP, Murphy WM. AO Principles of Fracture Management. Clavadelerstrasse, Davos Platz: AO Publishing, 2000.

23. Kowalski MJ, Schemitsch EH, Harrington RM, et al. A comparative biomechanical evaluation of a noncontacting plate and currently used devices for tibial fixation. J Trauma 1996;40:5-9.

24. Walpole SC, Prieto-Merino D, Edwards $\mathbf{P}$, et al. The weight of nations: an estimation of adult human biomass. BMC Public Health 2012;12:439

25. Chen JY, Zhou Z, Ang BF, et al. Drilling the near cortex with elongated figure-of-8 holes to reduce the stiffness of a locking compression plate construct. J Orthop Surg (Hong Kong) 2015;23:336-340.

26. Hopf T, Osthege S. Interfragmental compression of the Zespol osteosynthesis system. Experimental biomechanical studies. Z Orthop Ihre Grenzgeb 1987;125:546552. (In German) 
27. Granowski R, Ramotowski W, Kamiński E, Pilawski K. "Zespol"-a new type of osteosynthesis. I. An internal self-compressing stabilizer of bone fragments. Chir Narzadow Ruchu Ortop Po/ 1984;49:301-305. (In Polish)

28. Ramotowski W, Granowski R. Zespol. An original method of stable osteosynthesis. Clin Orthop Relat Res 1991;272:67-75.

29. Marti RK, van der Werken C. The A0-plate for external fixation in 12 cases. Acta Orthop Scand 1991;62:60-62.

30. Kerkhoffs GMMJ, Kuipers MM, Marti RK, Van der Werken C. External fixation with standard A0-plates: technique, indications, and results in 31 cases. J Orthop Trauma 2003;17:61-64

31. Kloen P. Supercutaneous plating: use of a locking compression plate as an external fixator. J Orthop Trauma 2009;23:72-75

32. Ebraheim NA, Carroll T, Hanna $\mathbf{M}$, et al. Staged treatment of proximal tibial fracture using external locking compression plate. Orthop Surg 2014;6:154-157.

33. Caja V, Kim W, Larsson S, E YC. Comparison of the mechanical performance of three types of external fixators: linear, circular and hybrid. Clin Biomech (Bristol, Avon) 1995;10:401-406.

34. Finlay JB, Moroz TK, Rorabeck CH, et al. Stability of ten configurations of the Hoffmann external-fixation frame. J Bone Joint Surg [Am]1987;69-A:734-744.

35. Moroz TK, Finlay JB, Rorabeck CH, Bourne RB. External skeletal fixation: choosing a system based on biomechanical stability. J Orthop Trauma 1988;2:284-296.

36. Windolf M, Klos K, Wähnert D, et al. Biomechanical investigation of an alternative concept to angular stable plating using conventional fixation hardware. BMC Musculoskelet Disord 2010;11:95.

37. Cordey J. An introduction to selected chapters in bone biomechanics. Injury 1999;30:A1-A6.

38. Miller DL, Goswami T. A review of locking compression plate biomechanics and their advantages as internal fixators in fracture healing. Clin Biomech (Bristol, Avon) 2007;22:1049-1062.

39. Moss DP, Tejwani NC. Biomechanics of external fixation: a review of the literature. Bull NYU Hosp Jt Dis 2007;65:294-299.

40. Niemeyer P, Südkamp NP. Principles and clinical application of the locking compression plate (LCP). Acta Chir Orthop Traumatol Cech 2006;73:221-228.

41. MacLeod A, Pankaj P. Computer Simulation of Fracture Fixation Using Extramedullary Devices: An Appraisal. In: Doyle B, Miller K, Wittek A, Nielsen PMF eds. Computational Biomechanics for Medicine: Fundamental Science and Patientspecific Applications. Springer: New York, 2014

42. MacLeod AR, Simpson AH, Pankaj P. Age-related optimization of screw placement for reduced loosening risk in locked plating. J Orthop Res 2016:34:1856 1864.

43. Cristofolini L, Viceconti M, Cappello A, Toni A. Mechanical validation of whole bone composite femur models. J Biomech 1996;29:525-535.

44. Heiner AD, Brown TD. Structural properties of a new design of composite replicate femurs and tibias. J Biomech 2001:34:773-781.

45. Calafi LA, Antkowiak T, Curtiss $\mathbf{S}$, et al. A biomechanical comparison of the Surgical Implant Generation Network (SIGN) tibial nail with the standard hollow nail. Injury 2010;41:753-757

\section{Funding Statement}

This study has been approved by the SingHealth Centralised Institutional Review Board $(2012 / 501 / D)$ and is funded with SGD 30,000 by the SingHealth Foundation Research Grant (SHF/FG469P/2011). The authors did not receive any other funding or grants in support of our research for or preparation of this work. Neither we nor a member of our immediate families received payments or other benefits or a commitment or agreement to provide such benefits from a commercial entity.

Author Contribution

B. F. H. Ang: Writing paper, Mechanical testing, Data analysis.

I. Y. Chen: Writing the paper, Mechanical testing, Data analysis.

A. K. S. Yew: Mechanical testing, Mechanical advice, Laboratory support, Data analysis, Amending the paper.

- S. K. Chua: Mechanical testing, Mechanical advice, Amending the paper

- S. M. Chou: Mechanical testing, Mechanical advice, Laboratory support, Amending the paper.

S. L. Chia: Amending the paper, Grant acquisition, Supervisory, Feedback.

J. S. B. Koh: Idea behind paper, Amending the paper, Grant acquisition, Supervisory, Feedback.

- T. S. Howe: Idea behind paper, Amending the paper, Grant acquisition, Supervisory, Feedback.

ICMJE Conflicts of Interest

- None declared.

(c) 2017 Ang et al. This is an open-access article distributed under the terms of the Creative Commons Attributions licence (CC-BY-NC), which permits unrestricted use, distribution, and reproduction in any medium, but not for commercial gain, provided the original author and source are credited. 